\title{
KEMANDIRIAN PUPUK SEBAGAI KUNCI KEBERHASILAN MEMBANGUN PERTANIAN ORGANIK
}

\author{
Supriyadi $^{1}$, Malihatun Nufus ${ }^{2}$, Sri Harati ${ }^{3}$, Purwanto $^{4}$, Galuh Masyithoh $^{5}$ \\ ${ }^{1}$ Universitas Sebelas Maret Surakarta \\ ${ }^{2}$ Universitas Sebelas Maret Surakarta \\ ${ }^{3}$ Universitas Sebelas Maret Surakarta \\ ${ }^{4}$ Universitas Sebelas Maret Surakarta \\ ${ }^{5}$ Universitas Sebelas Maret Surakarta
}

supriyadi_uns@staff.uns.ac.id, malihatunnufus@staff.uns.ac.id, srihartati59@staff.uns.ac.id, purwanto52@staff.uns.ac.id, galuhmasyhithoh@staff.uns.ac.id

\begin{abstract}
Abstrak
Pada era teknologi 4.0, perkembangan pertanian organik juga dituntut untuk dapat mengadopsi konsep-konsep baru, salah satunya adalah pertanian presisi. Pertanian presisi (Precision farming) adalah suatu teknik budidaya yang akurat, tertakar dan terukur ditingkat on farm. Pertanian presisi adalah pertanian yang efektif, efisien terkontrol dan terencana. Salah satu komponen pertanian presisi pada teknik budidaya padi organik adalah pupuk organik cair (POC). Dengan demikian pendampingan pengembangan Desa Organik Mandiri Pupuk oleh Perguruan Tinggi sangat diperlukan. Permasalahan yang dihadapi oleh petani padi organik adalah dalam mencukupi ketersediaan sarana produksi, salah satunya adalah ketersediaan pupuk organik cair (POC). Tujuan pengabdian adalah mengembangkan pupuk organik cair (POC) untuk memenuhi kebutuhan anggota kelompok tani padi organik. Secara garis beras metode pendekatan yang digunakan adalah dengan pendekatan Communitybased. Pendekatan community-based melibatkan peran serta masyarakat dalam setiap tahapan. Solusi untuk memenuhi kebutuhan pupuk organik cair (POC) adalah kelompok tani harus membuat sendiri POC yang memenuhi standart. Target luaran yang dicapai adalah memproduksi pupuk organik cair untuk seluruh anggota kelompok, sehingga kelompok tani menjadi mandiri dalam memenuhi kebutuhan pupuk.
\end{abstract}

Kata Kunci : padi organik, pupuk organik cair, kelompok tani

\section{PENDAHULUAN}

Pertanian organik adalah teknik budidaya pertanian yang mengandalkan bahan - bahan alami dengan tujuan utama adalah menyediakan bahan pangan yang aman bagi kesehatan produsen dan konsumennya serta tidak merusak lingkungan (Mayrowani, 2021). Gaya hidup sehat dengan syarat jaminan bahwa produk pertanian harus beratribut aman dikonsumsi, kandungan nutrisi tinggi dan ramah lingkungan (BPS, 2014). Menurut Badan Standardisasi Nasional (2013), "Organik" adalah istilah pelabelan yang menyatakan bahwa suatu produk sesuai dengan standar produksi organik dan disertifikasi. Pertanian organik merupakan sistem pertanian yang dapat mempertahankan sumber daya tanah, air dan udara agar dapat mendukung sistem pertanian dalam waktu yang tidak terbatas, karena itu sistem pertanin ini juga tidak bisa lepas dari aspek konservasi sehingga tujuan akhir berupa pertanian yang berkelanjutan akan terwujud.

Pada era teknologi 4.0, perkembangan pertanian organik juga dituntut untuk dapat 
mengadopsi konsep konsep baru, salah satunya adalaha pertanian presisi. Pertanian presisi (Precision farming) adalah suatu teknik budidaya yang akurat, tertakar dan terukur ditingkat on farm. Pertanian presisi adalah pertania yang efektif, efsisien terkontrol dan terencana. Manfaat utama pertanian presisi, diantaranya: pengaplikasian nutrisi yang tepat, akurat, tertakar dan terukur, pengaplikasian pestisida yang tepat, akurat, tertakar dan terukur, pemanfaatan sumber daya air, (VRT, variable rate irrigation), yang tepat, terkakar dan terukur, perencanaan yang tepat, akurat, tertakar dan terukur, kontrol atau pengendailain terhadap setiap kegiatan yang tepat, akurat tertakar dan terukur. Pertanian presisi utamanya ditujukan untuk produktivitas, hasil panen semaksimal mungkin, dengan pemanfaatan atau penggunaan sumber daya seefisien, dan seefektif mungkin, dimana teknologi menjadi tulang punggung atau kompenen utama dalam model tersebut.

Suatu produk dapat diakui sebagai produk organik apabila telah melalui proses sertifikasi oleh Lembaga Sertifikasi resmi. Departemen Pertanian Republik Indonesia juga telah menyusun standar pertanian organik di Indonesia, tertuang dalam SNI 01-6729-2013 (AOI, 2011). Persyaratan teknis produk pangan organik harus sesuai dengan standart regulasi teknis yang ditentukan oleh Peraturan Menteri Pertanian No.64 tahun 2013, tentang "Sistem Pertanian Organik" yang diberlakukan secara nasional tahun 2014, mencakup (a) budidaya pertanian, (b) Pengolahan, penyimpanan, penanganan dan transportasi produk pangan organik, (c) Label, pelabelan dan informasi pasar.. Salah satu program kerja kabinet kerja pemerintahan Presiden Joko Widodo-Jusuf Kala tahun 2015-2019 yang tertuang dalam Nawacita memberikan fokus kerja untuk meciptakan 1000 desa mandiri organik. Salah satu upaya adalah pengembangan Desa Organik Mandiri Pupuk. Kecamatan Susukan merupakan bagian wilayah kabupaten Semarang, terdapat 16 Kelompok Tani dan Gapoktan yang bergabung dalam Paguyuban PAGUYUBAN PETANI ORGANIK "AL BAROKAH", didirikan pada tanggal 14 September tahun 2004 dengan No. Akta Pendirian 24 .

Permasalahan teknis ataupun administratif yang teridentifikasi (mengacu kepada uraian situasi dan kondisi calon mitra) dalam setiap aspek bisnis mitra, yang mencakup bahan baku, produksi, proses, produk, manajemen, distribusi, pemasaran, sumberdaya manusia, fasilitas dan finansial. Solusi yang ditawarkan antara lain produk pupuk organik cair dilakukan secara mandiri, mengklasifikasi kualitas produk beras organik, melakukan pelatihan managemen pemasaran, pelatihan sumber daya manusia dan pengembangan modal usaha.

\section{METODE}

Secara garis besar metode pendekatan yang digunakan adalah dengan pendekatan Community-based. Pedekatan community-besed dipilih karena keterlibatan dan peran serta masyarakat (mitra) dalam setiap tahapan sangat diperlukan, menerapkan pendekatan Program Tindak Partisipatif (Partisipatory Action Program) dari peserta pada seluruh kegiatan PKM meliputi : diskusi, kerja bengkel/studio, operasional lahan, pelatihan dan pendampingan (kelompok dan individu). dan demonstrasi lapangan.

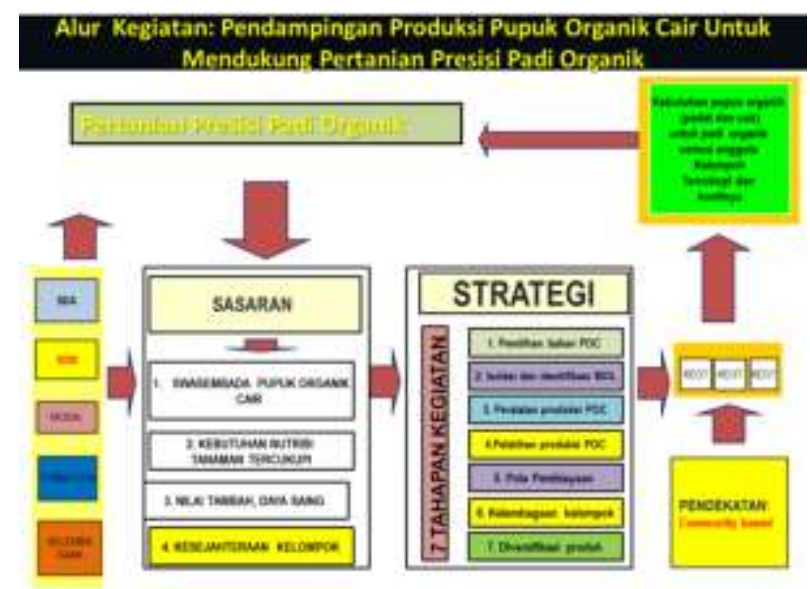

Gambar 1. Tahapan Pelaksanaan Kegiatan PKM

\section{HASIL DAN PEMBAHASAN}

\section{Pembuatan Bioreaktor Pupuk Organik Cair}

Pengelolaan Pertanian Terpadu (PTT) merupakan suatu upaya meningkatkan hasil pertanian dan efisiensi masukan produksi dengan memperhatikan penggunaan sumber daya alam secara bijak. Strategi peningkatan hasil ini ditempuh 
melalui cara mengelola tanaman, tanah, air, unsur hara dan organisme pengganggu tanaman secara holistik dan berkelanjutan. Salah satu aspek dalam konteks kritis ini, pengembangan mikroorganisme sebagai alternatif yang potensial untuk menjamin keberlanjutan produktivitas lahan, untuk mepertahankan keberlanjutan rantai makanan global. Biofertilzer berbasis carrier telah terbukti menjadi pilihan yang terbaik untuk subtitusiri bahan agro kimia dan telah menunjukkan efek luar biasa pada produktivitas pertanian global sejak dua dekade terakhir. Memperbaiki kelemahan dari biofertilizers berbasis carrier, biofertilizers cair (Liquid Microbial Consortium) perlu dikembangkan yang merupakan alternatif untuk pertanian berkelanjutan yang hemat biaya. Salah satu komponen yang harus tersedia adalah ketersedian pupuk, baik pupuk organik dan pupuk kimia, dalam bentuk padat atau cair. Untuk mengembangkan pupuk organik cair maka perlu ada instalasi pembuatan yang memadai. Konsep pembuatan Bioreaktor Pupuk Organik Cair di Kelompok Tani Al Mazroah sebagai berikut

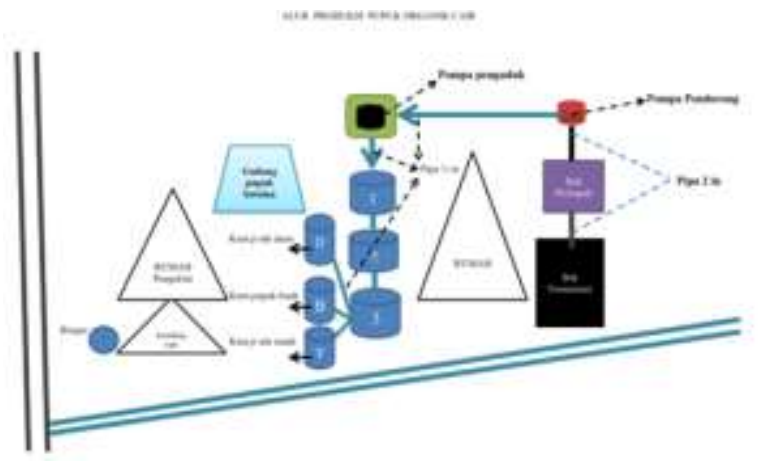

Gambar 2. Konsep Pengembangan POC

Konsep pengembangan POC di kelompok Tani Organik Al Mazroah, diwujudkan dalam bentuk bangunan Bioreaktor POC, tahap pembuatan Bioreaktor POC yang sudah dikerjakan, seperti gambar dibawah ini.

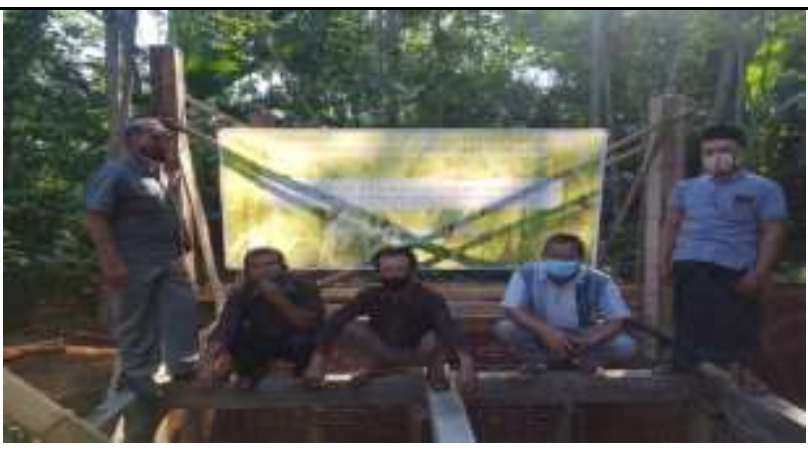

Gambar 3. Pembuatan Bioreaktor POC

Peralatan yang dibutuhkan antara lain: 1) bak fermentasi $2 \mathrm{mx} 4 \mathrm{~m}$ kedalaman $2 \mathrm{~m}$ dengan kontruksi beton bertutupkan asbes; 2) bak penyaring $1,5 \mathrm{mx} 2 \mathrm{~m}$ kedalaman $1 \mathrm{~m}$ dengan kontruksi beton bertutupkan asbes; 3) kaso untuk menahan tutup 2 bak; 4) pipa pralon 3 inc; 4) pompa pendorong dan pompa pengaduk; 5) stop kran 3/4;6) botol kemasan; 7) stiker label; 8) aliran listrik; 9) dan rak-rak botol pupuk.

\section{Pembuatan Pupuk Organik Cair}

Unit usaha organik, ini berfokus pada kegiatan produksi pupuk organik cair multifungsi, pupuk hayati dan agensia hayati,serta layanan pendidikan, pelatihan dan pendampingan pertanian organik. Pengembangan dan hilirisasi adalah sebagai berikut:

Tabel 1. Pengembangan dan Hilirisasi

\begin{tabular}{|c|c|c|c|}
\hline Bahan Baku & Kontinuitas & Mutu & $\begin{array}{l}\text { Alternatif } \\
\text { Sumber }\end{array}$ \\
\hline $\begin{array}{l}\text { Urine ternak } \\
\text { (sapi,kambing) }\end{array}$ & kontinyu & beragam & $\begin{array}{l}\text { Limbah } \\
\text { pertanian }\end{array}$ \\
\hline Isolat mikrobia & kontinyu & seragam & $\begin{array}{l}\text { Laboratorium } \\
\text { Biologi Tanah } \\
\text { dan Lab } \\
\text { Terpadu UNS }\end{array}$ \\
\hline $\begin{array}{l}\text { Bahan carrier } \\
\text { pupuk hayati : } \\
\text { gambut, } \\
\text { dolomit, zeolit }\end{array}$ & kontinyu & seragam & $\begin{array}{l}\text { Limbah } \\
\text { pertanian }\end{array}$ \\
\hline Tetes tebu & kontinyu & seragam & $\begin{array}{l}\text { Pabrik gula } \\
\text { Rumah }\end{array}$ \\
\hline Limbah rumen & kontinyu & seragam & $\begin{array}{l}\text { pemotongan } \\
\text { hewan }\end{array}$ \\
\hline Media & kontinyu & seragam & Laboratorium \\
\hline
\end{tabular}

Proses dan cara pembuatan pupuk organik cair (POC) adalah: 1) Bahan-bahan baku dimasukkan ke dalam bak fermentasi (1) selama 
kurang lebih 15 hari; 2) Setelah itu dari bak (1) fermentasi dialirkan ke dalam bak (2) sebagai penyaring; 3) Dari bak (2) penyaring, air hasil dari fermentasi didorong dengan pompa ke bak pengaduk selama kurang lebih 15 menit; 4) Dari bak (2) dialirkan dengan pompa ke tangki dan penampung; 5) Di dalam tangki penampung diberi tambahan nutrisi sesuai yang dibutuhkan setelah pengendapan / disaring; 6) Dari tangki penampung pengendapan /saring kemudian dialirkan ke tangki /drum2 kecil (sesuai klasifikasinya) untuk pupuk daun, pupuk buah dan pupuk tanah; 7) Dari ketiga tangki tersebut masing-masing diberi kran - kran untuk kemudian dimasukkan dalam kemasan botol sesuai dengan ukurannya :0,5 liter, 1 liter, dan 5 liter; 8) Setelah dikemas ke dalam botol kemudian di beri label, dicatat, diadministrasikan dan didistribusikan kepada : Anggota kelompok, Petani lain dan Pemesan dan distributor; 9) Produk pupuk dikelola dengan managemen organisasi dengan pembagian hasil: $60 \%$ pengelola, Kelompok $10 \%$, Paguyuban $10 \%$ dan Penguatan modal usaha $20 \%$.

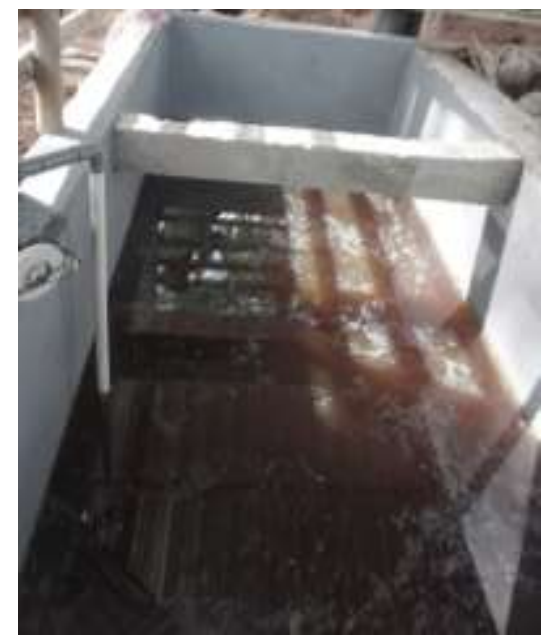

Gambar 4. Hasil Fermentasi Pupuk Organik Cair

Urine ternak sapi dan kambing merupakan salah satu bahan baku pembuatan pupuk orgamik cair. Manfaat urine sapi antara dapat merangsang pertumbuhan vegetatif tanaman karena urine sapi mengandung unsur hara makro dan mikro yang cukup dan dilengkapi dengan mikroorganisme lokal pengurai dan hormon yang dapat menyuburkan tanaman. Hal ini didukung oleh penelitian Masluki et al tahun 2016 bahwa penggunaan pupuk organik cair berbahan baku urine sapi mampu memberikan pertumbuhan dan produksi terbaik dari jenis bahan baku lainnya. Paramater yang dipengaruhi oleh urine sapi seperti tinggi tanaman, bobot kering pupus, bobot kering akar, panjang akar dan produksi tanaman padi (Masluki et al, 2016.

Tetes tebu yang terdapat dalam komposisi pembuatan pupuk organik cair berperan dalam pertumbuhan mikroba karena mengandung sumber karbon dan nitrogen dalam proses fermentasi. Molase dari tetes tebu mengandung karbohidrat yang cukup tinggi untuk kebutuhan mikroorganisme sehingga dijadikan bahan untuk sumber energi dalam proses fermentasi. Selain dijadikan sumber pertumbuhan mikroorganisme, tetes tebu juga mampu meningkatkan kandungan unsur hara terutama C-Organik untuk mengoptimalkan kualitas fermentasi pupuk organik cair menjadi lebih tinggi.

Limbah rumen juga sangat bermanfaat untuk pembuatan pupuk. Rumen sapi dibagi menjadi 2 yaitu dalam material padat dan cair. Rumen sapi padat merupakan bagian kasaran dari rumput-rumput yang belum dicerna sempurna oleh sapi di dalam lambung. Sedangkan rumen cair merupakan saringan dari rumen yang telah dibuang pada proses pemotongan. Cairan rumen sapi sangat kaya akan berbagai enzim seperti enzim selulase, amilase, protease, xilanase serta memiliki kandungan bakteri dengan konsentrasi $10^{9} / \mathrm{cc}$ dari isi rumen dan protozoa yang bervariasi sekitar $10^{5}$ $10^{6} / \mathrm{cc}$ dari isi rumen. Cairan isi rumen mengandung bahan organik yang tinggi. Kandungan bahan organik yang tinggi mempunyai potensi besar untuk dimanfaatkan sebagai pupuk organik atau kompos (Hudha et al, 2020).

\section{Hasil Analisis Kimia Pupuk Organik Cair}

Beberapa sampel dari pupuk organik cair diambil untuk dilakukan analisis laboratorium. Tujuan dari analisis tersebut untuk mengetahui apakah pupuk organik cair yang diproduksi sudah sesuai dengan standar baku mutu Kementerian Pertanian atau belum. Berikut adalah hasil analisis kimia pupuk organik cair.

Tabel 2. Hasil Analisis Kimia Pupuk Organik Cair 


\begin{tabular}{l}
\hline \multicolumn{5}{|c|}{ Bio Al-Barokah } \\
\begin{tabular}{|l|l|ll|l|}
\hline No & \multicolumn{1}{|c|}{ Kode } & \multicolumn{1}{|c|}{ Methode } & Hasil \\
\hline 1 & N-Total & Kjeldhal & $0,58 \%$ \\
\hline 2 & $\mathrm{P}_{2} \mathrm{O}_{5}$ & $\begin{array}{l}\text { Ekstraksi } \mathrm{HNO}_{3} \quad \text { dan } \\
\mathrm{HclO}_{4}\end{array}$ & $0,2 \%$ \\
\hline 3 & $\mathrm{~K}_{2} \mathrm{O}$ & $\begin{array}{l}\text { Ekstraksi } \mathrm{HNO}_{3} \quad \text { dan } \\
\mathrm{HclO}_{4}\end{array}$ & $0,56 \%$ \\
\hline 4 & C-Organik & Walkly \& Black & $2,67 \%$ \\
\hline 5 & Bahan Organik & Walkly \& Black & \\
\hline 6 & C/N Ratio & Kalkulasi & \\
\hline 7 & pH & Elektrode Glass & 6,55 \\
\hline
\end{tabular}
\end{tabular}

Sumber: Data Primer

Berdasarkan Keputusan Kementrian Pertanian RI Nomor 261/KPTS/SR.310/M/4/2019 menjelaskan bahwa persyaratan teknis minimal pupuk organik, pupuk hayati dan pembenah tanah adalah persyaratan komposisi dan kandungan hara yang harus dipenuhi oleh pupuk organik, pupuk hayati dan pembenah tanah yang ditetapkan oleh Menteri Pertanian. Syarat mutu pupuk dikelompokkan dalam pupuk organik padat, pupuk organik cair, pupuk hayati tunggal baik padat maupun cair, pupuk hayati majemuk baik padat maupun cair, pembenah tanah organik baik padat maupun cair, pembenah tanah fungsi khusus, pembenah tanah hayati dan senyawa humat. Maka dari itu, dengan mengetahui kompisisi yang terkandung dalam pupuk sangat penting untuk mempengaruhi tanah maupun tanaman.

Dari hasil analisis diatas dapat disimpulkan bahwa parameter yang terkandung dalam pupuk organik cair Bio Al-Barokah kurang memenuhi syarat dari standar baku mutu yang ditetapkan oleh Keputusan Kementrian Pertanian RI Nomor 261/KPTS/SR.310/M/4/2019. Total kandungan hara makro Bio Al-Barokah seperti N, P dan K hanya mencapai $1,34 \%$ dan perlu ditambahkan lebih banyak kandungan hara makro agar memenuhi syarat standar baku mutu. Selain kandungan hara makro, C-Organik yang terkandung juga perlu diperhatikan karena hasil yang diperoleh jauh dibawah standar yaitu hanya $2,67 \%$ dari syarat minimal $10 \%$. Terdapat salah satu parameter yang memenuhi standar baku mutu yang ditetapkan yaitu $\mathrm{pH}(6,55)$.

\section{Analisis Usaha Tani Pupuk Organik Cair}

Tabel 3. Biaya Usahatani Pupuk Organik Cair

\begin{tabular}{|c|c|c|c|c|}
\hline No & Jenis Biaya & $\begin{array}{l}\text { Unit/ } \\
\text { satuan }\end{array}$ & $\begin{array}{l}\text { Harga/unit } \\
\text { (Rp) }\end{array}$ & $\begin{array}{l}\text { Total } \\
\text { (Rp) }\end{array}$ \\
\hline \multirow[t]{4}{*}{1} & Biaya Tetap & & & \\
\hline & $\begin{array}{l}\text { a. Biaya } \\
\text { depresiasi alat }\end{array}$ & & & 10.000 .000 \\
\hline & b. Modal tetap & & & 15.000 .000 \\
\hline & $\begin{array}{l}\text { Biaya Tetap } \\
\text { Total }\end{array}$ & & & 25.000 .000 \\
\hline \multirow[t]{10}{*}{2} & Biaya Variabel & & & \\
\hline & $\begin{array}{l}\text { a. Pupuk } \\
\text { Kandang }\end{array}$ & $3.000 \mathrm{~kg}$ & 3.000 & 9.000 .000 \\
\hline & b. Tetes Tebu & 35 liter & 7.500 & 262.500 \\
\hline & c. Urine Ternak & 150 liter & 300 & 45.000 \\
\hline & d. Rumen Sapi & $30 \mathrm{~kg}$ & 5.000 & 150.000 \\
\hline & e. Pengkaya & 75 liter & 5.000 & 375.000 \\
\hline & g. Tenaga Kerja & 10 orang & 1.000 .000 & 10.000 .000 \\
\hline & h. Kemasan & 140 botol & 10.000 & 1.400 .000 \\
\hline & i. Label & $\begin{array}{r}100 \\
\text { lembar }\end{array}$ & 5.000 & 500.000 \\
\hline & $\begin{array}{l}\text { Biaya Variabel } \\
\text { Total }\end{array}$ & & & 21.732.500 \\
\hline 3. & Biaya Total & & & 46.732 .500 \\
\hline
\end{tabular}

Sumber: Data Primer

Tabel 3 menunjukkan bahwa biaya tetap total yang dikeluarkan dalam pembuatan pupuk organik cair sebesar Rp 25.000.000,- yang terdiri dari biaya depresiasi alat sebesar Rp 10.000.000,dan modal tetap sebesar Rp 15.000.000,-.

Biaya variabel total usahatani sebesar $\mathrm{Rp}$ 21.732.500,- yang terdiri dari biaya pupuk kandang sebesar Rp 9.000.000,- biaya tetes tebu sebesar Rp 262.500,- biaya urine ternak sebesar $\mathrm{Rp} 45.000$,biaya rumen sapi sebesar $\mathrm{Rp} 150.000$,- biaya pengkaya pupuk sebesar Rp 375.000,- biaya tenaga kerja sebesar Rp 10.000.000,- biaya kemasan sebesar Rp 1.400.000,- dan biaya label POC sebesar Rp 500.000,-.

Biaya total dalam usahatani produksi pupuk organik cair merupakan penjumlahan antara biaya tetap total dengan biaya variabel total. Biaya total di Desa Ketapang dalam Kelompok Tani Al- Mazroah sebesar Rp 46.732.500,--

Tabel 4. Biaya, Penerimaan dan Pendapatan Usahatani Pupuk Organik Cair

\begin{tabular}{|c|l|c|c|}
\hline No & \multicolumn{1}{|c|}{ Uraian } & Satuan & Nilai \\
\hline 1 & Biaya Tetap Total & $\mathrm{Rp}$ & 25.000 .000 \\
\hline 2 & Biaya Variabel Total & $\mathrm{Rp}$ & 21.732 .500 \\
\hline 3 & Biaya Total & $\mathrm{Rp}$ & 46.732 .500 \\
\hline
\end{tabular}




\begin{tabular}{|r|l|c|r|}
\hline 4 & Produksi & liter & 6.000 \\
\hline 5 & Harga Jual & $\mathrm{Rp} / \mathrm{Kg}$ & 10.000 \\
\hline 6 & Penerimaan Total & $\mathrm{Rp}$ & 60.000 .000 \\
\hline 7 & Pendapatan & $\mathrm{Rp}$ & 13.267 .500 \\
\hline
\end{tabular}

Sumber: Data Primer

Tabel 4 menunjukkan bahwa biaya total yang dikeluarkan dalam pembuatan pupuk organik cair sebesar $\mathrm{Rp}$ 46.732.500,- dengan demikian pendapatan Kelompok Tani Al-Mazroah sebesar Rp13.267.500,-.

R/C Usahatani Pupuk Ogranik Cair

$\mathrm{R} / \mathrm{C}$ merupakan perbandingan antara penerimaan total dengan biaya total dan digunakan untuk melihat kelayakan dari usahatani yang dijalankan. R/C pada usahatani pupuk organik cair di Desa Ketapang, Kecamatan Susukan, Kabupaten Semarang sebagai berikut :

$$
\begin{aligned}
\mathrm{R} / \mathrm{C} & =\frac{\text { Penerimaan Total }}{\text { Biaya Total }} \\
& =\frac{60.000 .000}{46.732 .500} \\
& =1,28
\end{aligned}
$$

R/C pada usahatani kacang tanah setiap kali produksi di Desa Ketapang sebesar 1,28 menunjukkan bahwa usahatani kacang tanah tersebut menguntungkan untuk diusahakan, karena terbukti memberikan keuntungan kepada petani. R/C 1,28 menunjukkan bahwa setiap Rp 1, biaya yang dikeluarkan pada usahatani tersebut memperoleh penerimaan sebesar Rp 1,28, sehingga pendapatan yang diperoleh sebesar $\mathrm{Rp} 0,28$.

\section{KESIMPULAN}

Bahan baku pembuatan pupuk organik cair Bio Al-Barokah meliputi urine ternak (sapi dan kambing), rumen sapi, isolat mikroba, bahan carrier pupuk hayati (gambut, dolomit, zeolit) dan tetes tebu.

Kandungan unsur hara pada pupuk organik cair Bio Al-Barokah belum memenuhi persyaratan standar baku mutu yang ditetapkan oleh Keputusan Kementrian Pertanian RI Nomor 261/KPTS/SR.310/M/4/2019.

Biaya total yang dikeluarkan pada produksi pupuk organik cair dalam Kelompok Tani AlMazroah di Desa Ketapang Kecamatan Susukan
Kabupaten Semarang sebesar Rp 46.732.500,-, penerimaan sebesar Rp 60.000.000,- sehinggan pendapatan yang diperoleh sebesar Rp 13.267.500,-.

R/C usahatani dalam Kelompok Tani AlMazroah di Desa Ketapang Kecamatan Susukan Kabupaten Semarang sebesar 1,28 yang artinya setiap Rp 1,- biaya yang dikeluarkan pada produksi tersebut akan memperoleh penerimaan sebesar Rp 1,28 ,- sehingga pendapatan yang diperoleh sebesar Rp 0,28,-. Hal ini menunjukkan bahwa produksi pupuk organik cair tersebut menguntungkan sehingga layak untuk diusahakan.

\section{UCAPAN TERIMAKASIH}

Penulis mengucapkan terimakasih kepada LPPM Universitas Sebelas Maret Surakarta yang telah mendanai dan mendukung pengabdian ini sehingga dapat terlaksana.

\section{REFERENSI}

AOI. (2011). Produsen dan Produk Organik Bersertifikat Meningkat. Bogor. http://www.organicindonesia.org/05infodat a-news.php?id=221. Diunduh 2 September 2015.

BPS Jawa Tengah. (2014). Jawa Tengah Dalam Angka Tahun 2015. Badan Pusat Statistik. Semarang.

Hudha, Istnaeny et al. 2020. Pemanfaatan Limbah Isi Rumen Sapi sebagai Mikroorganisme Lokal (MOL). Atmosphere 1 (1) : 30-36 [33]

Masluki, Muhammad Naim dan Mutmainnah. (2016). Pemanfaatan Pupuk Organik Cair (POC) pada Lahan Sawah Melalui Sistem Mina Padi. Prosiding Seminar Hasil 2 (1) : 866-874.

Mayrowani, H. (2012). Pengembangan Pertanian Organik di Indonesia. Forum Penelitian Agro Ekonomi. Vol : 30 No. 2. Desember $2012: 91-108$. 